\title{
PENGARUH BRAND PERSONALITY TERHADAP LOYALITAS PELANGGAN SAMPO SUNSILK (Survei pada Mahasiswi FPIPS UPI Bandung Angkatan 2004-2006)
}

\author{
Hari Mulyadi \\ Devi Saktiawati
}

\begin{abstract}
Abstrak
Persaingan bisnis di lini produk sampo kian hari kian kompetitif sehingga menuntut tiap perusahaan untuk mempertahankan pelanggannya. Usaha yang dilakukan oleh Sunsilk untuk mempertahankan pelanggannya tidak lagi terbatas pada atribut fungsional produk seperti kegunaan produk, melainkan sudah dikaitkan dengan keberadaan merek yang mampu menciptakan citra khusus dalam benak pemakainya. Penciptaan brand personality dalam benak pelanggan akan menciptakan loyalitas pelanggan. Penelitian ini bertujuan untuk mengetahui brand personality, loyalitas pelanggan, serta pengaruh brand personality terhadap loyalitas pelanggan sampo sunsilk.

Berdasarkan variabel yang diteliti maka jenis penelitian ini adalah penelitian deskriptif dan verifikatif. Metode pengembangan penelitian bersifat cross sectional method. Populasi penelitian ini berjumlah 540 orang yang merupakan mahasiswi FPIPS UPI angkatan 2004-2006 pengguna sampo sunsilk. Berdasarkan teknik penarikan sampel secara simple random sampling dan dengan menggunakan rumus Harun Al Rasyid diperoleh sampel sebesar 48 sampel, namun untuk meningkatkan keakuratan maka jumlah sampel yang diteliti ditambah sehingga berjumlah 80 sampel. Data yang digunakan adalah data primer dan sekunder dengan teknik pengumpulan data melalui wawancara, observasi, penyebaran kuesioner dan studi literatur. Pengujian hipotesis dilakukan dengan menggunakan path analysis dengan bantuan software komputer SPSS 15.0.

Hasil penelitian menunjukkan brand personality sampo sunsilk secara umum berkategori cukup baik dengan dimensi brand personality yang paling tinggi skornya ialah competence. Loyalitas pelanggan sampo sunsilk secara umum sudah berkategori cukup baik dengan dimensi loyalitas pelanggan yang memiliki skor paling tinggi adalah frekuensi pembelian (pembelian berulang). Brand personality memiliki pengaruh yang positif terhadap loyalitas pelanggan dimana dimensi competence memiliki kontribusi yang paling tinggi.
\end{abstract}

\section{Kata Kunci: Brand Personality dan Loyalitas Pelanggan}

\section{PENDAHULUAN}

Implikasi dari kehadiran era globalisasi adalah persaingan antar industri menjadi semakin ketat akibat perubahan teknologi, ekonomi, dan kondisi situasi pasar yang terjadi hampir di setiap sektor industri. Demikian pula dengan kondisi perekonomian di Indonesia. Meningkatnya kondisi perekonomian masyarakat Indonesia telah mengakibatkan munculnya industri-industri yang berusaha untuk memenuhi kebutuhan setiap konsumen baik dalam bentuk barang maupun jasa.

Persaingan dalam dunia bisnis saat ini, semakin lama semakin tinggi. Persaingan dalam memperebutkan dan mempertahankan konsumen menjadi semakin sulit. Hal ini terlihat dari semakin banyaknya alternatif produk yang dapat dipilih oleh konsumen. Munculnya produk-produk yang inovatif secara terus menerus dalam waktu yang relatif singkat menuntut perusahaan untuk berupaya mengembangkan produknya agar tidak tertinggal oleh pesaing-pesaingnya.

Hal tersebut berlaku juga pada industri toiletries (industri yang memproduksi produk perawatan pribadi), para produsen dalam industri ini dituntut untuk melakukan inovasi bisnis yang baru agar dapat mengungguli para pesaing, dengan menghasilkan produk yang diinginkan dan dapat diterima oleh konsumen. Pada saat sekarang ini konsumen tidak lagi hanya mengharapkan kualitas yang tinggi dari suatu produk, tetapi juga manfaat yang akan mereka terima dari produk tersebut.

Salah satu kategori produk dalam industri toiletries adalah sampo. Beberapa dasawarsa terakhir, industri ini diwarnai oleh beberapa persaingan yang tinggi, sehingga konsumen 
dihadapkan pada beberapa jenis sampo dengan berbagai variasi merek, kemasan, harga serta kualitasnya.

Fenomena tersebut merupakan peluang bagi perusahaan atau industri toiletries untuk mengembangkan usahanya.

Tabel 1 di bawah memperlihatkan perusahaan dan produk yang termasuk ke dalam industri toiletries.

Tabel 1

Perusahaan dan Produk Sampo

\begin{tabular}{|c|c|c|}
\hline UNILEVER & P \& G & OTHER \\
\hline Sunsilk & Pantene & Emeron (Wings) \\
\hline Dove & Head \& Shoulders & Zinc (Wings) \\
\hline Clear & Rejoice & Natur (Gondowangi) \\
\hline Lifebuoy & Herbal Essences & Metal Fortis \\
\hline
\end{tabular}

Sumber: SWA 16/XXII/23 Juli-5 Agustus 2008

Berdasarkan Tabel 1 di atas, dapat dilihat bahwa industri sampo merupakan salah satu dari sekian banyak industri yang menggambarkan ketatnya persaingan. Persaingan industri toiletries, khususnya sampo di Indonesia dikuasai oleh dua perusahaan besar yaitu Unilever dan P\&G. Produk-produk dari kedua perusahaan tersebut sudah dikenal dalam ingatan konsumen sampo. Dalam industri sampo banyak perusahaan menggunakan beberapa merek dalam masingmasing segmen untuk menjangkau lebih banyak target pasar.

Salah satu yang termasuk ke dalam industri toiletries (industri produk perawatan pribadi) adalah Unilever yang mengeluarkan produk sampo. Strategi pendekatan yang dilakukan PT Unilever tak sekadar pada fungsi produk, tapi juga produk dan kemasan yang beragam sehingga bisa masuk ke semua segmen usia. Konsep pemasaran Sunsilk tidak canggung, dari awal, Sunsilk ditujukan bagi kalangan bawah sampai ke atas. Segmen pasar ini lebih berpotensi menyerap produk berkualitas dan mementingkan manfaat atau nilai yang diterima dari suatu produk oleh karena itu Unilever selalu berusaha mengembangkan inovasi teknologi maupun terobosanterobosan baru. Namun usaha tersebut belum memberikan kontribusi yang berarti dalam usaha mempertahankan kesetiaan pelanggan. Hal ini dapat dibuktikan dengan indeks loyalitas pelanggan dari sampo yang mengalami penurunan.
Adapun indeks loyalitas pelanggan produk sampo dapat dilihat pada Tabel 2.

Tabel 2

Indeks Loyalitas Pelanggan Produk Sampo Tahun 2008

\begin{tabular}{|c|c|c|c|}
\hline Merek sampo & $\mathbf{2 0 0 6}$ & $\mathbf{2 0 0 7}$ & $\mathbf{2 0 0 8}$ \\
\hline Pantene & 86,4 & 82,8 & 81,6 \\
\hline Dove & 79,2 & 81,8 & 82,3 \\
\hline Sunsilk & $\mathbf{8 6 , 8}$ & $\mathbf{8 1 , 4}$ & $\mathbf{8 0 , 3}$ \\
\hline
\end{tabular}

Sumber: SWA 17/XXIII/6Agustus-20 Agustus 2008

Berdasarkan Tabel 2 di atas loyalitas sunsilk mengalami penurunan dari tahun ke tahun yaitu sebesar $5,4 \%$ pada tahun 2006 sebesar $86,8 \%$ menjadi $81,4 \%$ pada tahun 2007 dan pada tahun 2008 mengalami hal yang sama yaitu penurunan sebesar $1,1 \%$ menjadi $80,3 \%$. Hal yang sama dialami oleh Pantene sebesar 1,2\% pada tahun 2008 menjadi 81,6\%. Sementara untuk Dove mengalami peningkatan sebesar $0,5 \%$. Penurunan loyalitas ini menunjukan siklus hidup yang semakin pendek dimana konsumen dapat dengan mudah berpindah merek dari satu merek ke merek lainnya, dikarenakan penawaran yang lebih dari pesaing baik dalam hal varian, harga serta manfaat yang ditawarkan. Hal ini harus menjadi pertimbangan bagi perusahaan untuk dapat meningkatkan loyalitas pelanggan melalui kualitas produk, manfaat yang ditawarkan oleh produk itu sendiri.

Sunsilk dalam mempertahankan konsumen tidak lagi terbatas pada atribut fungsional produk seperti kegunaan produk, melainkan sudah dikaitkan dengan merek yang mampu memberikan citra khusus bagi pemakainya sehingga menciptakan sebuah kesadaran akan merek dan menimbulkan kepuasan pelanggan.

Dalam mengukur kepuasan konsumen, terdapat beberapa parameter yaitu:

1. Quality Satisfaction Score (QSS): untuk mempertanyakan tingkat kepuasan terhadap kualitas produk atau jasa.

2. Value Satisfaction Score (VSS): untuk mengukur nilai yang diberikan produk, termasuk kepuasan terhadap pertimbangan harga berdasarkan kualitas yang diterima dari produk atau jasa yang digunakan.

3. Perceived Best Score (PBS): untuk menilai sejauh mana produk atau jasa dipersepsi sebagai merek terbaik dibanding merek lainnya, sedangkan Total Satisfaction Score 


\section{StrategiC}

(TTS): total kumulasi nilai dari ketiga parameter tersebut.

(Majalah SWA 19/XXIII/3-12 September 2007)

Skor QSS, VSS dan PBS masing-masing merek diukur dengan menggunakan skala Likert 15. Untuk QSS dan VSS, skor $1=$ sangat tidak puas, $2=$ tidak puas, $3=$ biasa saja, $4=$ puas, $5=$ sangat puas, sedangkan untuk PBS, skor $1=$ paling buruk, 2 = buruk, 3 = biasa saja, $4=$ baik, 5 $=$ paling baik. TSS diperoleh dengan menggunakan metode weighted means (rata-rata berbobot) dari QSS, VSS dan PBS.

Merek yang baik akan dapat menciptakan kesetiaan yang mutlak dengan cara melampaui harapan para pelanggan dan menyenangkan. Seorang Pemasar (marketer) diharuskan untuk memahami bagaimana kepribadian (personality) mempengaruhi perilaku konsumsi karena pengetahuan akan hal ini memungkinkan mereka untuk lebih memahami konsumen dan untuk mengetahui pangsa serta konsumen sasaran yang merespon secara positif produk mereka.

Agar konsumen setia terhadap suatu merek, maka terlebih dahulu harus tercipta kepuasan konsumen. Karena bagaimanapun konsumen merupakan penentu kehidupan dan masa depan suatu produk atau jasa.

Tabel 3 di bawah ini memperlihatkan penurunan kepuasan pelanggan produk sampo 2006-2008. tahun berturut-turut yaitu pada tahun 2007-2008 memiliki tingkat kepuasan konsumen kedua setelah kompetitornya yaitu Clear yang memiliki tingkat kepuasan konsumen yang tertinggi. Hal ini menandakan ketatnya persaingan dalam memperebutkan kesetiaan dari pelanggan masingmasing merek sampo, sehingga bukan hal yang tidak mungkin apabila pelanggan dari sampo Sunsilk berpindah merek ke sampo lain. Kesetiaan pelanggan bisa menjadi barometer kelangsungan perusahaan. Karena dengan memiliki pelanggan setia, perusahaan mendapat jaminan produknya akan terus dibeli dan bisnis ke depan akan berjalan lancar.

Kepuasan pelanggan (customer satisfaction) tidak selalu memberikan jaminan bahwa konsumen akan loyal. Walaupun konsumen sudah sangat puas terhadap kualitas produk/jasa, ternyata masih banyak juga yang berpindah ke merek lain. Hal ini disebabkan karena diferensiasi di antara merekmerek yang tersedia tidak terlalu signifikan. Sehingga untuk konsumen, tidak ada resiko untuk berpindah merek. Alasan lain mengapa konsumen yang puas tidak selalu loyal, adalah karena adanya suatu tawaran insentif yang menarik dari kompetitor yang sulit untuk ditolak oleh konsumen. Dalam kondisi ini, loyalitas ke merek awal menjadi turun.

Saat ini bila para produsen tidak memfokuskan diri dalam memenuhi kepuasan pelanggan sebagai

Tabel 3

Indeks Kepuasan Pelanggan Produk Sampo 2006-2008

\begin{tabular}{|c|c|c|c|c|c|c|c|c|c|c|c|c|c|c|c|}
\hline $\begin{array}{l}\mathrm{N} \\
\mathrm{O}\end{array}$ & Merek & $\begin{array}{l}\text { QSS } \\
2006\end{array}$ & $\begin{array}{l}\text { VSS } \\
2006\end{array}$ & $\begin{array}{l}\text { PBS } \\
2006\end{array}$ & $\begin{array}{c}\text { TSS } \\
2006\end{array}$ & Merek & $\begin{array}{l}\text { QSS } \\
2007\end{array}$ & $\begin{array}{l}\text { VSS } \\
2007\end{array}$ & $\begin{array}{l}\text { PBS } \\
2007\end{array}$ & $\begin{array}{c}\text { TSS } \\
2007\end{array}$ & Merek & $\begin{array}{l}\text { QSS } \\
2008\end{array}$ & $\begin{array}{l}\text { VSS } \\
2008\end{array}$ & $\begin{array}{l}\text { PBS } \\
2008\end{array}$ & $\begin{array}{l}\text { TSS } \\
2008\end{array}$ \\
\hline 1 & Sunsilk & 4,088 & 3,968 & 4,047 & 3,960 & Clear & 4,158 & 4,073 & 4,104 & 4,028 & Clear & 4,143 & 4,039 & 4,127 & 4,030 \\
\hline 2 & Clear & 4,067 & 3,935 & 4,026 & 3,942 & Sunsilk & 4,097 & 4,025 & 4,082 & 3,978 & Sunsilk & 4,040 & 4,019 & 4,093 & 3,990 \\
\hline 3 & Pantene & 4,014 & 3,834 & 3,997 & 3,894 & Pantene & 4,045 & 3,912 & 4,025 & 3,908 & Pantene & 4,101 & 3,971 & 4,067 & 3,976 \\
\hline 4 & Dove & 3,988 & 3,769 & 3,948 & 3,852 & Lifebuoy & 3,993 & 3,902 & 3,930 & 3,853 & Dove & 4,018 & 3,866 & 3,981 & 3,887 \\
\hline 5 & Lifebuoy & 3,932 & 3,894 & 3,920 & 3,039 & Dove & 3,939 & 3,789 & 3,894 & 3,804 & Lifebuoy & 3,931 & 3,858 & 3,931 & 3,842 \\
\hline 6 & Rejoice & 3,920 & 3,799 & 3,891 & 3,812 & Rejoice & 3,915 & 3,789 & 3,871 & 3,779 & $\begin{array}{l}\text { Head \& } \\
\text { Should. }\end{array}$ & 3,936 & 3,520 & 3,853 & 3,739 \\
\hline 7 & & & & & & $\begin{array}{l}\text { Head \& } \\
\text { Should. }\end{array}$ & 3,942 & 3,943 & 3,897 & 3,824 & Rejoice & 3,881 & 3,775 & 3,801 & 3,733 \\
\hline 8 & & & & & & Emeron & 3,779 & 3,746 & 3,695 & 3,636 & Zinc & 3,778 & 3,755 & 3,785 & 3,712 \\
\hline 9 & & & & & & & & & & & Emeron & 3,554 & 3,559 & 3,585 & 3,543 \\
\hline
\end{tabular}

Berdasarkan tabel di atas, pada tahun 2006 Sunsilk memiliki tingkat kepuasan tertinggi dibanding kompetitornya akan tetapi, Sunsilk mengalami penurunan kepuasan pelanggan 2 dampak dari keunggulan bersaing, maka dapat dipastikan perusahaan akan tergeser oleh pesaingpesaingnya. Kepuasan pelanggan semakin diperlukan karena konsumen semakin mudah untuk berpindah dari satu merek ke merek yang 
lain, sehingga perilaku loyal dari konsumen akan semakin sulit untuk diwujudkan. Oleh karena itu diperlukan strategi khusus untuk mengatasi masalah tesebut.

Adapun salah satu cara yang dapat ditempuh dalam membangun loyalitas pelanggan dengan cara menciptakan brand personality, karena kebanyakan konsumen memperoleh kepribadian merek dari produk yang mereka gunakan. Setiap jenis produk memiliki kepribadian yang berbeda dan ingin mewakili setiap tipe konsumen yang berbeda atau untuk situasi yang berbeda. Konsumen akan cenderung mencari produk dengan kepribadian yang mendekati kemiripan atau kesesuaian dengan diri mereka.

Sunsilk berharap melalui brand personality yang melekat pada brand ambassador yaitu Sunsilk menunjuk Madonna, Marylin Monroe sebagai global brand ambassador dan Krisdayanti sebagai lokal brand ambassador untuk memperkenalkan semangat perubahan besar tersebut mampu menarik minat konsumen. Sunsilk beranggapan bahwa banyak kesempatan dan kejadian penting yang harus diputuskan seorang perempuan saat mereka berusia usia 20 tahun. Sunsilk mengerti bahwa rambut tidak hanya sebagai simbol bagi seorang perempuan dalam mengekspresikan identitas dirinya, namun juga mempunyai sebuah kekuatan emosional yang ada dalam diri setiap perempuan untuk menjalani hidupnya. Promosi yang dilakukan Sunsilk melalui iklan ini diharapkan dapat membangun loyalitas pelanggan terhadap produk dan dapat menciptakan brand personality Sunsilk di benak konsumen.

Seorang perempuan merasa bahagia dengan rambutnya, bahkan mampu mengatakan karakter dirinya, maka akan melahirkan energi positif untuk menjalani hidup. Berdasarkan riset Sunsilk yang di lakukan di Indonesia menemukan fakta bahwa $97 \%$ perempuan berpendapat rambut memiliki peran penting dalam penampilan, yang membuatnya lebih bahagia dan tampil percaya diri.

Penelitian dilakukan pada mahasiswa FPIPS UPI Bandung karena berdasarkan hasil pra penelitian yang dilakukan oleh peneliti, Sunsilk mengalami penurunan pelanggan dari 667 menjadi 540 orang. Hal ini berarti setidaknya terdapat 127 orang yang berpotensi besar untuk berpindah merek. Penurunan jumlah pengguna menunjukan adanya permasalahan dalam loyalitas Mahasiswi
FPIPS UPI Angkatan 2004-2006 terhadap Sunsilk. Untuk melihat adanya penurunan loyalitas dapat dilihat dalam Tabel 4 di bawah ini:

Tabel 4

Jumlah Pengguna Sampo Sunsilk di FPIPS UPI Angkatan 2004-2006

\begin{tabular}{|l|c|c|c|}
\hline Jurusan/Program & $\begin{array}{c}\text { Tahun } \\
2006\end{array}$ & $\begin{array}{c}\text { Tahun } \\
2007\end{array}$ & $\begin{array}{c}\text { Tahun } \\
2008\end{array}$ \\
\hline $\begin{array}{l}\text { Pendidikan Manajemen } \\
\text { Bisnis }\end{array}$ & 89 & 85 & 76 \\
\hline $\begin{array}{l}\text { Pendidikan Administrasi } \\
\text { Perkantoran }\end{array}$ & 72 & 64 & 53 \\
\hline Manajemen & 62 & 66 & 48 \\
\hline Akuntansi & 74 & 68 & 59 \\
\hline $\begin{array}{l}\text { Pendidikan Ekonomi } \\
\text { Koperasi }\end{array}$ & 80 & 65 & 58 \\
\hline Pendidikan Akuntansi & 96 & 89 & 78 \\
\hline $\begin{array}{l}\text { Pendidikan Pancasila } \\
\text { dan Kewarganegaraan }\end{array}$ & 68 & 51 & 42 \\
\hline Sejarah & 46 & 32 & 25 \\
\hline Geografi & 43 & 35 & 29 \\
\hline $\begin{array}{l}\text { Manajemen Pemasaran } \\
\text { Pariwisata }\end{array}$ & 41 & 36 & 24 \\
\hline $\begin{array}{l}\text { Manajemen Resort dan } \\
\text { Leisure }\end{array}$ & $\mathbf{3 7}$ & $\mathbf{3 4}$ & $\mathbf{2 1}$ \\
\hline $\begin{array}{l}\text { Manajemen Industri } \\
\text { Katering }\end{array}$ & $\mathbf{4 5}$ & $\mathbf{4 2}$ & $\mathbf{2 7}$ \\
\hline \begin{tabular}{l} 
Total Keseluruhan \\
\hline
\end{tabular} & 753 & 667 & 540 \\
\hline Sumber Survei Pengolanan Data 2008 & & \\
\hline
\end{tabular}

Sumber: Survei Pengolahan Data 2008

Berdasarkan Tabel 4 di atas dapat terlihat bagaimana pelanggan dapat mudah berpindah ke merek lain. Hal ini dapat disebabkan diantaranya pelanggan merasa kurang puas akan sampo Sunsilk baik manfaat yang diterima maupun dari faktor lain. Di samping itu Kompetitor lain bisa saja menawarkan nilai lebih dari produk mereka sehingga dapat memberikan manfaat yang lebih dari produk mereka untuk menarik minat pelanggan dari merek lain sehingga pelanggan cenderung berpindah ke merek lain. Keadaan ini yang harus dicermati Sunsilk agar kompetitor tidak mengambil peluang dari pelanggan yang merasa kurang puas terhadap produk Sunsilk.

Berdasarkan uraian yang telah disampaikan sebelumnya, maka penelitian ini merumuskan masalah pokok sebagai berikut:

1. Bagaimana gambaran brand personality pada pelanggan sampo Sunsilk Mahasiswi FPIPS UPI Bandung Angkatan 2004-2006. 
2. Bagaimana gambaran loyalitas pelanggan sampo Sunsilk pada Mahasiswi FPIPS UPI Bandung Angkatan 2004-2006.

3. Seberapa besar pengaruh brand personality terhadap loyalitas pelanggan sampo Sunsilk Mahasiswi FPIPS UPI Bandung Angkatan 2004-2006.

\section{KERANGKA PEMIKIRAN}

Setiap perusahaan berusaha memenuhi kebutuhan konsumen secara lebih baik dengan menggunakan berbagai strategi pemasaran dengan tujuan memenangkan persaingan. Dalam hal ini, keberhasilan suatu perusahaan tergantung pada kemampuan perusahaan tersebut dalam menciptakan strategi pemasaran yang tepat dan efektif.

Merek merupakan suatu identitas yang merupakan tanda atau ciri yang dipergunakan oleh seorang produsen untuk membedakan produk yang dihasilkannya dengan produk pesaingnya. Tanda ataupun ciri ini kemudian membentuk suatu kepribadian yang dikenal dengan brand personality (kepribadian merek).

Sebuah merek kemudian harus memiliki karakteristik tertentu. Merek harus dikenal karena sesuatu, dihubungkan dengan sesuatu. Hal ini berkaitan dengan positioning merek tersebut di benak pelanggan. Banyak riset yang ditujukan untuk menentukan bagaimana posisi suatu merek dibandingkan posisi merek pesaingnya dalam hal sesuatu yang dianggap sebagai karakteristik merek yang menonjol. Hermawan kertajaya (2000:443) menyatakan bahwa " Brand juga punya fungsi membedakan kualitas yang satu dengan yang lain, agar konsumen bisa tahu perbedaannya. Brand juga jadi jaminan dari produsen atas hasil karyanya. Karena itu, produsen tak boleh sembarangan membuat produk".

Terdapat lima indikator brand personality yang dikemukakan oleh Kotler \& Amstrong (2006:140)

1. Sincerity (ketulusan), yaitu karakter yang jujur, rendah hati, dan sederhana. Sincerity tertuang dalam kejujuran dalam kualitas, keaslian produk, dan keidentikan merek dengan sifatsifat yang sederhana, seperti ceria dan berjiwa muda.

2. Excitement (semangat) berarti karakter dinamis yang penuh semangat dan imajinasi yang tinggi dalam melakukan perbedaan dan inovasi.

3. Competence (kemampuan), yaitu kemampuan untuk dapat diandalkan dan dipercaya oleh pelanggan.

4. Sophistication (keduniawian), yaitu karakteristik yang berkaitan dengan eksklusifitas yang dibentuk oleh keunggulan prestise, citra merek, maupun tingkat daya tarik yang mempesona.

5. Ruggedness (ketangguhan), yaitu karakteristik merek yang dikaitkan dengan manfaat suatu merek dalam menunjang kegiatan luar rumah dan kekuatan atau daya tahan produk.

Gambaran kepribadian merespon kecenderungan dalam masyarakat zaman sekarang untuk menilai hubungan pribadi. Hal tersebut juga mengandung arti bahwa hubungan merupakan hal yang penting dalam kehidupan sosial. Dalam hierarki Maslow, brand personality dimaksudkan agar mengangkat produk ke tingkat yang lebih tinggi yaitu kebutuhan akan kepuasan, rasa memiliki, cinta dan penghargaan (Ouwersloot dan Tudorica, 2001:2).

Konsep loyalitas lebih mengarah kepada perilaku dibandingkan dengan sikap dan seorang pelanggan yang loyal akan memperhatikan perilaku pembelian yang dapat diartikan sebagai pola pembelian yang teratur dan dalam waktu yang lama, yang dilakukan oleh unit-unit pembuat atau pengambil keputusan. Loyalitas pelanggan bisa memberikan dampak pertumbuhan pendapatan dan profitabilitas bagi perusahaan. Loyalitas pelanggan memiliki peran penting dalam sebuah organisasi perusahaan.

Memiliki pelanggan yang loyal adalah suatu hal yang sangat berharga bagi perusahaan. Beberapa karakteristik konsumen yang loyal menurut Griffin (2005;31), yaitu :

1. Melakukan pembelian secara teratur

2. Membeli diluar lini produk atau jasa

3. Merekomendasikan produk kepada orang lain

4. Menunjukan kekebalan dari daya tarik produk atau jasa sejenis dari pesaing

Pada dasarnya ada 2 perspektif utama dalam mendefinisikan dan mengukur loyalitas. Menurut Fandy Tjiptono $(2001 ; 109)$ yaitu loyalitas sebagai perilaku dan loyalitas sebagai sikap. Dengan kata lain, loyalitas dapat ditinjau dari merek produk/jasa apa yang dibeli konsumen dan bagaimana perasaan (sikap konsumen) terhadap merek 
tersebut. Seorang pemasar (marketer) harus memahami bagaimana personality mempengaruhi perilaku konsumsi, karena pengetahuan akan hal ini memungkinkan mereka untuk lebih memahami konsumen, pangsa pasar, serta konsumen sasaran.

Merek yang memiliki brand personality yang unggul dan sesuai dengan personality konsumen tentunya akan menciptakan ikatan di antara merek dengan konsumen tersebut. Hal ini dikarenakan brand personality bisa berguna untuk menganalisis perilaku atas suatu produk maupun pilihan merek. Kotler \& Amstrong (2006:140) menjelaskan dasar pemikiran dari brand personality adalah bahwa baik merek maupun manusia memiliki kepribadian, dan manusia sebagai konsumen cenderung memilih merek dengan kepribadian yang sesuai dengan kepribadiannya.

Pengaruh positif brand personality terhadap loyalitas pelanggan dikemukakan oleh Gobe (2005:150-151) yang menjelaskan bahwa merekmerek dengan brand personality yang kuat memiliki daya tarik yang kuat pula, daya tarik yang dapat dimanfaatkan untuk menciptakan ikatan emosional sehingga pelanggan merasa dekat dengan merek dan menganggap suatu merek tertentu sebagai bagian aktifitas hidupnya. Dengan tercipta ikatan emosional yang tinggi, pelanggan tidak akan mudah berganti merek karena pelanggan menjadi loyal terhadap merek tersebut.

\section{METODE PENELITIAN}

Penelitian ini meneliti pengaruh brand personality sebagai variabel bebas (independent variabel) terhadap loyalitas pelanggan sebagai variabel terikat (dependent variabel). Brand personality yang diteliti adalah kepribadian suatu merek yang berdasarkan pada sincerity (ketulusan hati), excitement (kegembiraan), competence (kemampuan), sophistication (keduniawian), ruggedness (ketangguhan). Sedangkan loyalitas pelanggan meliputi pembelian berulang, pembelian antar lini produk dan jasa, referensikan kepada orang lain, kekebalan terhadap tarikan dari pesaing.

Berdasarkan variabel yang diteliti maka jenis penelitian dalam peneitian ini adalah penelitian deskriptif dan verifikatif. Metode penelitian yang digunakan adalah deskriptive dan explanatory survey. Jangka waktu penelitian kurang dari satu tahun, yaitu dimulai dari Juli 2007 sampai dengan Desember 2007, maka metode pengembangannya bersifat cross sectional methode. Menurut Husein Umar (2001:45) cross sectional methode merupakan metode penelitian dengan cara mempelajari objek dalam kurun waktu tertentu (tidak berkesinambungan dalam jangka waktu panjang).

Populasi penelitian ini adalah mahasiswa FPIPS UPI angkatan 2004-2006 pengguna sampo Sunsilk sebesar 540 mahasiswa. Berdasarkan teknik penarikan sampel secara simple random sampling dan dengan menggunakan rumus Harun Al Rasyid diperoleh sampel sebesar 48 sampel, namun untuk meningkatkan keakuratan maka jumlah sampel yang diteliti ditambah sehingga berjumlah 80 sampel. Menurut Winarno Surakhmad (1998:100), untuk jaminan ada baiknya sampel selalu ditambah sedikit lagi dari jumlah matematik.

Tabel 5 di bawah ini menyajikan operasionalisasi variabel penelitian.

Tabel 5

Operasionalisasi Variabel

\begin{tabular}{|c|c|c|c|c|c|}
\hline Variabel & Sub variabel & Konsep variabel & Indikator & Ukuran & Skala \\
\hline $\begin{array}{l}\text { Brand } \\
\text { Personality } \\
\text { (X) }\end{array}$ & & $\begin{array}{l}\text { Brand personality adalah suatu } \\
\text { gabungan dari sifat manusia } \\
\text { yang dapat diterapkan pada } \\
\text { suatu merek" } \\
\text { (Kotler \& Amstrong, 2006:140) }\end{array}$ & & & \\
\hline & \multirow[t]{4}{*}{$\begin{array}{l}\text { Sincerity } \\
\text { (Ketulusan) }\end{array}$} & \multirow[t]{4}{*}{$\begin{array}{l}\text { Karakter yang jujur, rendah hati, } \\
\text { dan sederhana } \\
\text { (Kotler \& Amstrong, 2006:140) }\end{array}$} & $\begin{array}{l}\text { - Kesesuaian kualitas yang } \\
\text { diiklankan Sunsilk dengan } \\
\text { kenyataan }\end{array}$ & $\begin{array}{l}\text { - Tingkat kesesuaian kualitas } \\
\text { yang diiklankan Sunsilk } \\
\text { dengan kenyataan }\end{array}$ & Ordinal \\
\hline & & & - Kealamian bahan Sunsilk & $\begin{array}{ll}\text { - } & \text { Tingkat kealamian bahan } \\
\text { Sunsilk }\end{array}$ & Ordinal \\
\hline & & & $\begin{array}{l}\text { - Keidentikan Sunsilk dengan } \\
\text { suasana ceria }\end{array}$ & $\begin{array}{l}\text { - Tingkat keidentikan Sunsilk } \\
\text { dengan suasana ceria }\end{array}$ & Ordinal \\
\hline & & & $\begin{array}{l}\text { - Keidentikan Sunsilk dengan usia } \\
\text { muda }\end{array}$ & $\begin{array}{l}\text { - Tingkat keidentikan Sunsilk } \\
\text { dengan usia muda }\end{array}$ & Ordinal \\
\hline & $\begin{array}{l}\text { Excitement } \\
\text { (Ketertarikan) }\end{array}$ & $\begin{array}{l}\text { Karakter dinamis yang penuh } \\
\text { semangat dan imajinasi yang }\end{array}$ & - Keunikan kemasan Sunsilk & $\begin{array}{l}\text { - Tingkat keunikan kemasan } \\
\text { Sunsilk }\end{array}$ & Ordinal \\
\hline
\end{tabular}




\begin{tabular}{|c|c|c|c|c|c|}
\hline Variabel & Sub variabel & Konsep variabel & Indikator & Ukuran & Skala \\
\hline & & \multirow[t]{2}{*}{$\begin{array}{l}\text { tinggi dalam melakukan } \\
\text { perbedaan dan inovasi } \\
\text { (Kotler \& Amstrong, 2006:140) }\end{array}$} & $\begin{array}{l}\text { - Daya imajinatif Sunsilk dalam } \\
\text { menciptakan berbagai jenis } \\
\text { pilihan sampo } \\
\end{array}$ & $\begin{array}{l}\text { - Tingkat daya imajinatif Sunsilk } \\
\text { dalam menciptakan berbagai } \\
\text { jenis pilihan sampo } \\
\end{array}$ & Ordinal \\
\hline & & & $\begin{array}{l}\text { Kecepatan } \\
\text { Sunsilk dalam melakukan } \\
\text { pengembangan produk } \\
\end{array}$ & $\begin{array}{l}\text { - Tingkat kecepatan } \\
\text { Sunsilk dalam melakukan } \\
\text { pengembangan produk }\end{array}$ & Ordinal \\
\hline & \multirow[t]{4}{*}{$\begin{array}{l}\text { Competence } \\
\text { (Kemampuan) }\end{array}$} & \multirow{4}{*}{$\begin{array}{l}\text { Kemampuan untuk dapat } \\
\text { diandalkan dan dipercaya oleh } \\
\text { pelanggan } \\
\text { (Kotler \& Amstrong, 2006:140) }\end{array}$} & $\begin{array}{l}\text { - Kepercayaan pelanggan } \\
\text { terhadap kualitas Sunsilk }\end{array}$ & $\begin{array}{l}\text { - Tingkat kepercayaan } \\
\text { pelanggan terhadap kualitas } \\
\text { Sunsilk } \\
\end{array}$ & Ordinal \\
\hline & & & $\begin{array}{l}\text { - Kepercayaan terhadap } \\
\text { pengalaman Sunsilk }\end{array}$ & $\begin{array}{l}\text { - Tingkat kepercayaan terhadap } \\
\text { pengalaman Sunsilk }\end{array}$ & Ordinal \\
\hline & & & - Keamanan kandungan Sunsilk & $\begin{array}{l}\text { - Tingkat keamanan kandungan } \\
\text { Sunsilk } \\
\end{array}$ & Ordinal \\
\hline & & & $\begin{array}{l}\text { - Kemudahan menggunakan } \\
\text { Sunsilk }\end{array}$ & $\begin{array}{ll}\text { - } & \text { Tingkat kemudahan } \\
\text { menggunakan Sunsilk }\end{array}$ & Ordinal \\
\hline & \multirow[t]{3}{*}{$\begin{array}{l}\text { Sophistication } \\
\text { (Keduniawian) }\end{array}$} & \multirow{3}{*}{$\begin{array}{l}\text { Karakteristik yang berkaitan } \\
\text { dengan eksklusifitas yang } \\
\text { dibentuk oleh keunggulan } \\
\text { prestise, citra merek maupun } \\
\text { tingkat daya tarik yang } \\
\text { mempesona } \\
\text { (Kotler \& Amstrong, 2006:140) }\end{array}$} & $\begin{array}{l}\text { - Gengsi yang dirasakan } \\
\text { pelanggan dari penggunaan } \\
\text { Sunsilk }\end{array}$ & $\begin{array}{l}\text { - Tingkat gengsi yang dirasakan } \\
\text { pelanggan dari penggunaan } \\
\text { Sunsilk }\end{array}$ & Ordinal \\
\hline & & & $\begin{array}{l}\text { - Perbedaan citra merek Sunsilk } \\
\text { dibanding merek lain }\end{array}$ & $\begin{array}{l}\text { - Tingkat perbedaan citra merek } \\
\text { Sunsilk dibanding merek lain }\end{array}$ & Ordinal \\
\hline & & & $\begin{array}{l}\text { - Daya tarik wewangian Sunsilk } \\
\text { yang mewah }\end{array}$ & $\begin{array}{l}\text { - Tingkat daya tarik wewangian } \\
\text { Sunsilk yang mewah } \\
\end{array}$ & Ordinal \\
\hline & \multirow[t]{2}{*}{$\begin{array}{l}\text { Ruggedness } \\
\text { (Ketangguhan) }\end{array}$} & \multirow{2}{*}{$\begin{array}{l}\text { Karakteristik merek yang } \\
\text { dikaitkan dengan manfaat suatu } \\
\text { merek dalam menunjang } \\
\text { kegiatan luar rumah dan } \\
\text { kekuatan atau daya tahan } \\
\text { produk } \\
\text { (Kotler \& Amstrong, 2006:140) }\end{array}$} & $\begin{array}{l}\text { - Manfaat Sunsilk dalam } \\
\text { mendukung aktifitas luar rumah }\end{array}$ & $\begin{array}{l}\text { - Tingkat manfaat Sunsilk } \\
\text { dalam mendukung aktifitas } \\
\text { luar rumah }\end{array}$ & Ordinal \\
\hline & & & - Daya tahan produk Sunsilk & $\begin{array}{l}\text { - Tingkat daya tahan produk } \\
\text { Sunsilk }\end{array}$ & Ordinal \\
\hline \multirow[t]{5}{*}{$\begin{array}{l}\text { Loyalitas } \\
\text { Pelanggan } \\
\text { (Y) }\end{array}$} & & $\begin{array}{l}\text { "Loyalitas pelanggan adalah } \\
\text { pembelian nonrandom yang } \\
\text { diungkapkan dari waktu ke } \\
\text { waktu oleh beberapa unit } \\
\text { pengambilan keputusan" } \\
\text { (Griffin, 2005:5) }\end{array}$ & & & \\
\hline & & & - Pembelian ulang Sunsilk & $\begin{array}{l}\text { - Tingkat pembelian ulang } \\
\text { Sunsilk }\end{array}$ & Ordinal \\
\hline & & & $\begin{array}{l}\text { - Pembelian antar lini produk } \\
\text { Sunsilk }\end{array}$ & $\begin{array}{l}\text { - Tingkat pembelian antar lini } \\
\text { produk Sunsilk }\end{array}$ & Ordinal \\
\hline & & & - Referensi terhadap orang lain & $\begin{array}{l}\text { - Tingkat referensi terhadap } \\
\text { orang lain }\end{array}$ & Ordinal \\
\hline & & & $\begin{array}{l}\text { - Kekebalan terhadap daya tarik } \\
\text { pesaing }\end{array}$ & $\begin{array}{l}\text { - Tingkat kekebalan terhadap } \\
\text { daya tarik pesaing }\end{array}$ & Ordinal \\
\hline
\end{tabular}

Sumber : Berdasarkan Hasil Pengolahan Data dan Referensi Buku

Pemecahan masalah akan dilakukan dengan menggunakan dua analisis, yaitu analisis deskriptif dan analisis verifikatif.

Analisis deskriptif dapat digunakan untuk mencari kuatnya hubungan antara variabel melalui analisis korelasi dan membuat perbandingan dengan membandingan rata-rata data sampel atau populasi tanpa perlu diuji signifikansinya (Sugiyono, 2006:144). Analisis deskriptif bertujuan mengubah kumpulan data mentah menjadi mudah dipahami dalam bentuk informasi yang lebih ringkas. Sedangkan analisis verifikatif dilakukan dengan melakukan pengujian hipotesis dengan menggunakan path analysis (analisis jalur). Analisis jalur digunakan untuk menentukan besarnya pengaruh variabel independen brand personality $(\mathrm{X})$ yang terdiri atas sincerity, excitement, competence, sophistication, ruggedness terhadap variabel dependen $(Y)$ yaitu loyalitas pelanggan.

\section{HASIL PENELITIAN DAN PEMBAHASAN}

Hasil penelitian dan pembahasan akan disajikan secara terurut. Dimulai dengan deskripsi variabel penelitian, kemudian pengujian hipotesis, serta diakhiri dengan penyajian mengenai implikasi penelitian ini terhadap bidang kajian yang diteliti.

1. DESKRPSI VARIABEL PENELITAN

- Rekapitulasi Tanggapan terhadap Brand Personality Sampo Sunsilk

Jurnal Strategic, Volume 7, Nomor 13, Februari 2008 


\section{StrategiC}

Tabel 22 berikut ini menyajikan data

personality Sampo Sunsilk.

rekapitulasi tanggapan responden terhadap brand

Tabel 6

Rekapitulasi Skor Tanggapan Responden terhadap Brand Personality Sampo Sunsilk

\begin{tabular}{|c|c|c|c|}
\hline No & Variabel/Dimensi & Skor & Rata-Rata \\
\hline \multirow{6}{*}{1} & Sincerity (Ketulusan Hati) & & \\
\hline & Kesesuaian kualitas Sunsilk yang diiklankan dengan kenyataan. & 313 & \\
\hline & Kandungan bahan yang digunakan Sunsilk. & 307 & \\
\hline & Keidentikan Sunsilk dengan keceriaan. & 289 & \\
\hline & Keidentikan Sunsilk dengan usia muda. & 305 & \\
\hline & Sub total & 1214 & 303,5 \\
\hline \multirow{5}{*}{2} & Excitement (Kegembiraan) & & \\
\hline & Keunikan kemasan Sunsilk & 308 & \\
\hline & Kreatifitas Sunsilk dalam menciptakan berbagai pilihan jenis sampo. & 306 & \\
\hline & Kecepatan Sunsilk dalam melakukan pengembangan produk. & 283 & \\
\hline & Sub total & 897 & 299 \\
\hline \multirow{6}{*}{3} & Competence (Kemampuan) & & \\
\hline & Kepercayaan anda terhadap kualitas Sampo Sunsilk. & 306 & \\
\hline & $\begin{array}{l}\text { Kepercayaan anda pada pengalaman Sunsilk yang telah diproduksi } \\
\text { bertahun-tahun. }\end{array}$ & 302 & \\
\hline & Keamanan Sampo Sunsilk. & 315 & \\
\hline & Kemudahan menggunakan Sampo Sunsilk. & 298 & \\
\hline & Sub total & 1221 & 305,25 \\
\hline \multirow{5}{*}{4} & Sophistication (Keduniawian) & & \\
\hline & $\begin{array}{l}\text { Gengsi yang anda rasakan dari penggunaan Sampo Sunsilk } \\
\text { dibandingkan dengan merek lain. }\end{array}$ & 324 & \\
\hline & Perbedaaan citra merek Sampo Sunsilk dibandingkan dengan merek lain. & 303 & \\
\hline & Daya tarik wewangian Sampo Sunsilk yang mewah. & 287 & \\
\hline & Sub total & 914 & 304,66 \\
\hline \multirow{3}{*}{5} & Ruggedness (Ketangguhan) & & \\
\hline & Manfaat Sampo Sunsilk dalam mendukung aktifitas anda di luar rumah. & 318 & \\
\hline & Daya tahan produk Sampo Sunsilk. & 290 & \\
\hline \multirow{2}{*}{\multicolumn{2}{|c|}{$\begin{array}{rr} & \text { Sub total } \\
\text { Total Skor Brand Personality Sampo Sunsilk }\end{array}$}} & 608 & 304 \\
\hline & & 4854 & 1516,41 \\
\hline
\end{tabular}

Sumber: Berdasarkan Hasil Pengolahan Data 2008

Secara keseluruhan variabel brand personality dapat diketahui kedudukannya berdasarkan skor yang di dapat berdasarkan data dari Tabel di atas, di mana nilai-nilai tersebut dibandingkan dengan kriteria skor standar, yang di dapat melalui perhitungan skor ideal (criterium) dan skor terkecil, sehingga melalui skor standar tersebut dapat diketahui daerah kontinium yang menunjukkan wilayah ideal dari variabel brand personality, hal tersebut dapat dicari dengan rumus menurut Sugiono (2006:94) sebagai berikut: Mencari skor ideal Brand Personality:

Skor ideal $\Rightarrow$ Skor Tertinggi $x$ Jumlah Butir Item $x$

$$
\text { Jumlah Pengguna }
$$

Skor ideal $\Longrightarrow 5 \times 16 \times 80=6400$

Mencari skor Terendah Brand Personality:

\begin{tabular}{|c|}
\hline $\begin{array}{c}\text { Skor ideal } \Longrightarrow \text { Skor Terendah } \mathrm{x} \text { Jumlah Butir Item } \\
\text { Jumlah Pengguna }\end{array}$ \\
\hline Skor ideal $\Longrightarrow 1 \times 16 \times 80=1280$ \\
\hline Mencari Panjang Interval Kelas Brand Personality: \\
\hline $\begin{array}{l}\text { Panjang Interval Kelas } \longrightarrow \begin{array}{l}\text { Skor Ideal : Banyaknya } \\
\text { Kelas Interval }\end{array} \\
\text { Panjang Interval Kelas } \longrightarrow 6400: 5=1280\end{array}$ \\
\hline
\end{tabular}

Berdasarkan jumlah skor hasil pengumpulan data Brand Personality adalah 4854 lihat Tabel 4.25 dengan demikian maka Brand Personality menurut tanggapan dari 80 pengguna adalah (4854:6400) x 100\% = 75,84\%

Nilai 4854 sesuai dengan data penelitian yaitu termasuk dalam kategori sedang dan tinggi tetapi lebih mendekati tinggi, jadi brand personality 


\section{StrategiC}

sampo sunsilk termasuk dalam kategori cukup tinggi atau cukup baik.

\section{- Rekapitulasi Tanggapan terhadap Loyalitas Pelanggan Sampo Sunsilk}

Tabel 29 berikut ini menyajikan data rekapitulasi tanggapan responden terhadap loyalitas pelanggan Sampo Sunsilk.

Secara keseluruhan variabel loyalitas pelanggan sampo sunsilk dapat diketahui kedudukannya berdasarkan skor yang di dapat berdasarkan data dari Tabel di atas, di mana nilainilai tersebut dibandingkan dengan kriteria skor standar, yang di dapat melalui perhitungan skor ideal (criterium) dan skor terkecil, sehingga melalui skor standar tersebut dapat diketahui daerah kontinium yang menunjukkan wilayah ideal dari variabel loyalitas pelanggan sampo sunsilk.

Berdasarkan jumlah skor hasil pengumpulan data loyalitas pelanggan adalah 1738 lihat Tabel 4.32 dengan demikian maka loyalitas pelanggan sampo sunsilk menurut tanggapan dari 80 pengguna adalah $(1738: 2400) \times 100 \%=72,41 \%$.

Nilai 1738 sesuai dengan data penelitian yaitu termasuk dalam kategori sedang dan tinggi tetapi lebih mendekati tinggi, jadi loyalitas sampo sunsilk termasuk dalam kategori cukup tinggi atau cukup baik.

Tabel 7

Rekapitulasi Skor Tanggapan Responden terhadap Loyalitas Pelanggan Sampo Sunsilk

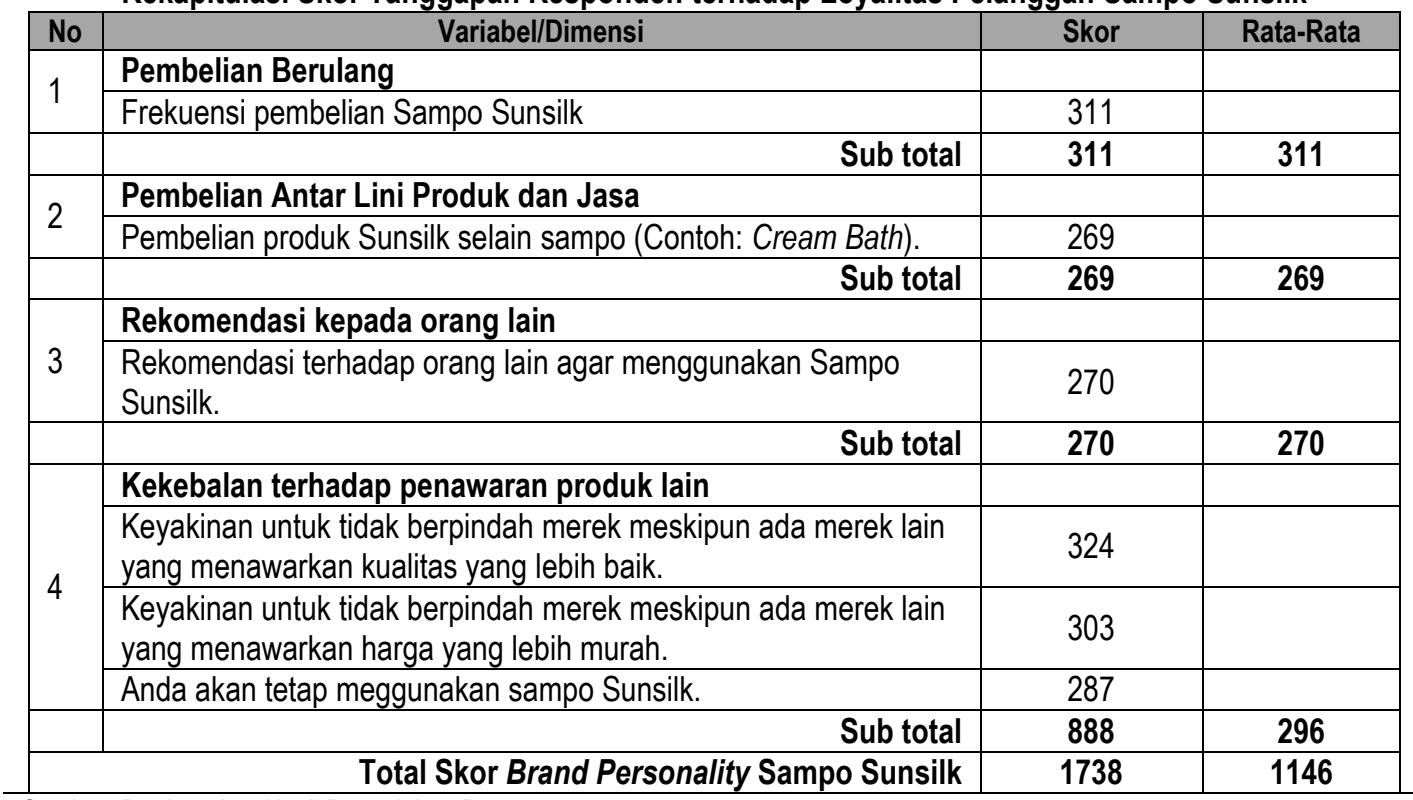

Sumber: Berdasarkan Hasil Pengolahan Data 2008

\section{HASIL PENGUJIAN HIPOTESIS}

Pengujian Hipotesis Penelitian Pengaruh Brand Personality Terhadap Loyalitas pelanggan

Pada penelitian ini hanya terdapat satu hipotesis yang diuji yaitu pengaruh Brand Personality terhadap loyalitas pelanggan. Pengujian hipotesis ditujukan untuk menguji pengaruh brand personality yang terdiri dari sincerity (ketulusan hati), excitement (kegembiraan), competence (kemampuan), sophistication (keduniawian), ruggedness (ketangguhan) terhadap loyalitas pelanggan ( $\mathrm{Y}$ ). Pengujian hipotesis ini dilakukan dengan bantuan software SPSS 15 dan menggunakan uji statistik path analysis (analisis jalur) dengan cara menganalisis hubungan pengaruh antara total skor item sincerity $\left(X_{1}\right)$, excitement $\left(X_{2}\right)$, competence $\left(X_{3}\right)$, sophistication $\left(X_{4}\right)$, ruggedness $\left(X_{5}\right)$ terhadap loyalitas pelanggan $(\mathrm{Y})$.

Tabel 8

Matrik Korelasi antara Dimensi Brand Personality dengan Loyalitas Pelanggan

\begin{tabular}{|c|c|c|c|c|c|c|}
\hline & $\mathbf{Y}$ & $\mathbf{X}_{\mathbf{1}}$ & $\mathbf{X}_{\mathbf{2}}$ & $\mathbf{X}_{\mathbf{3}}$ & $\mathbf{X}_{\mathbf{4}}$ & $\mathbf{X}_{\mathbf{5}}$ \\
\hline $\mathbf{Y}$ & - & 0,492 & 0,484 & $\mathbf{0 , 6 5 0}$ & 0,452 & 0,439 \\
\hline $\mathbf{X}_{1}$ & 0,492 & - & 0,503 & 0,255 & 0,378 & 0,373 \\
\hline $\mathbf{X}_{2}$ & 0,484 & 0,503 & - & 0,219 & 0,606 & 0,399 \\
\hline
\end{tabular}

Jurnal Strategic, Volume 7, Nomor 13, Februari 2008 


\section{StrategiC}

\begin{tabular}{|c|c|c|c|c|c|c|}
\hline $\mathbf{X}_{3}$ & 0,650 & 0,255 & 0,219 & - & 0,325 & 0,222 \\
\hline $\mathbf{X}_{4}$ & 0,452 & 0,378 & $\mathbf{0 , 6 0 6}$ & 0,325 & - & 0,457 \\
\hline $\mathbf{X}_{5}$ & 0,439 & 0,373 & 0,399 & 0,222 & 0,457 & - \\
\hline
\end{tabular}

Sumber: Hasil pengolahan Data 2008

Berdasarkan hasil pengujian hipotesis diketahui bahwa korelasi terbesar antara setiap dimensi $X$ dengan $Y$ diperoleh competence sebagai $\left(X_{3}\right)$ dan loyalitas pelanggan sebagai $(Y)$ dengan nilai 0,650 . Berdasarkan interprestasi koefisien korelasi menunjukan bahwa terdapat hubungan yang sangat kuat antara dimensi competence dengan loyalitas pelanggan.

Sedangkan nilai koefisien korelasi terbesar antar setiap dimensi $X$ dimiliki oleh pada korelasi antara excitement $\left(X_{2}\right)$ dan sophistication $\left(X_{4}\right)$ dengan nilai 0,606 . Hal tersebut menunjukan bahwa terdapat hubungan yang signifikan antara excitement dengan sophistication.

Berdasarkan hasil pengujian untuk uji $F$ melalui program SPSS 15 diperoleh data pengujian keseluruhan pada tabel Anova menunjukkan tingkat signifikan, yang menunjukkan $F_{\text {hitung }}>F_{\text {tabel, }}$ yaitu 23,399 > 3,964 sehingga dapat diambil kesimpulan Ho ditolak oleh karena itu pengujian secara individual dapat dilakukan.

Selanjutnya adalah pengujian secara individual dengan melihat koefisien korelasi jalur $X$ terhdap $Y$ dengan menggunakan program SPSS 15 diperoleh ouput koefisien jalur.

Adapun untuk pengujian koefisien jalur setiap variabel diperoleh dalam Tabel 31 berikut ini:

\section{Tabel 9}

Hasil Pengujian Koefisien Jalur

\begin{tabular}{|c|c|c|c|c|}
\hline \multicolumn{2}{|c|}{ Koefisien Jalur } & thitung & t tabel & Kesimpulan \\
\hline PYX.1 & 0,290 & 2,195 & 1,994 & Ho Ditolak \\
\hline PYX.2 & 0,252 & 2,545 & 1,994 & Ho Ditolak \\
\hline PYX.3 & 0,312 & 6,736 & 1,994 & Ho Ditolak \\
\hline PYX.4 & 0,183 & 2,152 & 1,994 & Ho Ditolak \\
\hline PYX.5 & 0,170 & 2,695 & 1,994 & Ho Ditolak \\
\hline
\end{tabular}

Sumber : Hasil Pengolahan Data 2008

Berdasarkan hasil pengujian koefisien jalur diperoleh pengaruh sincerity terhadap Loyalitas pelanggan memiliki nilai 0,290 , pengaruh excitement terhadap loyalitas pelanggan memiliki nilai 0,252 , pengaruh competence terhadap loyalitas pelanggan memiliki nilai 0,312 , pengaruh sophistication terhadap loyalitas pelanggan memiliki nilai 0,183 , dan pengaruh ruggedness terhadap loyalitas pelanggan memiliki nilai 0,170 . Pengaruh terbesar ada pada pengaruh competence terhadap loyalitas pelanggan, thitung yang diperoleh dengan tingkat signifikansi 0.05 yaitu 2,195, 2,545, 6,736, 2,152, 2,695 dengan tabel 1,994 Jadi dapat disimpulkan bahwa $X_{1}, X_{2}, X_{3}, X_{4}$, dan $X_{5}$ Ho ditolak yang artinya terdapat pengaruh antara sincerity, excitement, competence, sophistication dan ruggedness terhadap loyalitas pelanggan.

Hasil pengujian seluruh pengaruh brand personality terhadap loyalitas pelanggan disajikan pada Tabel 9 sebagai berikut.

Tabel 10

Hasil Pengujian Pengaruh Diferensiasi Produk

Terhadap Keputusan Pembelian

\begin{tabular}{|c|c|c|c|c|}
\hline $\begin{array}{c}\text { Pengaruh } \\
\text { Variabel }\end{array}$ & $\begin{array}{l}\text { Koefisien } \\
\text { Jalur }\end{array}$ & $\begin{array}{l}\text { Pengaruh } \\
\text { Langsung }\end{array}$ & $\begin{array}{c}R^{2} Y X_{1}, \\
\ldots, Y X_{5}\end{array}$ & $\begin{array}{l}\text { Pengujian } \\
\text { Hipotesis }\end{array}$ \\
\hline$X_{1}$ terhadap $Y$ & 0,290 & 0,0841 & 0,1824 & Ho Ditolak \\
\hline $\mathrm{X}_{2}$ terhadap $\mathrm{Y}$ & 0,252 & 0,0635 & 0,1625 & Ho Ditolak \\
\hline $\mathrm{X}_{3}$ terhadap $\mathrm{Y}$ & 0,312 & 0,0973 & 0,1679 & Ho Ditolak \\
\hline $\mathrm{X}_{4}$ terhadap $\mathrm{Y}$ & 0,183 & 0,0335 & 0,1143 & Ho Ditolak \\
\hline$X_{5}$ terhadap $Y$ & 0,170 & 0,0289 & 0,0904 & Ho Ditolak \\
\hline \multicolumn{3}{|c|}{$R^{2}$} & 0,7175 & \\
\hline
\end{tabular}

Sumber : Hasil Pengolahan Data 2008

Berdasarkan hasil perhitungan diatas maka pengaruh brand personality termasuk kategori kuat, untuk koefisien jalur variabel lainnya diluar variabel $\mathrm{X}_{1}, \mathrm{X}_{2}, \mathrm{X}_{3}, \mathrm{X}_{4}$ dan $\mathrm{X}_{5}$ ditentukan melalui:

$$
\begin{aligned}
P_{Y \in} & =\sqrt{1-R^{2} Y\left(x_{1}, x_{2}, x_{3}, x_{4}, x_{5}\right)} \\
& =\sqrt{1-0,7275} \\
& =0,53150729
\end{aligned}
$$

Artinya $X_{1}, X_{2}, X_{3}, X_{4}$, dan $X_{5}$, secara bersamasama mempengaruhi $Y$ adalah $71,75 \%$ dan sisanya sebesar $(0,53150729)^{2}=0,2825 \times 100 \%$ $=28,25 \%$ dipengaruhi oleh faktor lain yang tidak termasuk dalam penelitian.

Berdasarkan data pada Tabel 33 dapat diambil kesimpulan terdapat pengaruh brand personality terhadap loyalitas pelanggan. Dapat dilihat nilai pengaruh langsung dari $X$ terhadap $Y$, nilai pengaruh tidak langsung, nilai total pengaruh dan nilai thitung terhadap alpha dengan tingkat kesalahan 0,05 sehingga dapat disimpulkan keseluruhan Ho ditolak dan Ha diterima. Sehingga disimpulkan bahwa adanya pengaruh brand personality terhadap loyalitas pelanggan sampo Sunsilk. 
Tabel 1

Hasil Pengujian Koefisien Jalur Pengaruh Langsung dan Tidak Langsung Dimensi Variabel $\mathbf{X}$ terhadap $Y$

\begin{tabular}{|c|c|c|c|c|c|c|c|c|c|c|c|c|}
\hline \multirow{2}{*}{$X$} & \multirow{2}{*}{$\begin{array}{c}\text { Pengaruh } \\
\text { Langsung } \\
\text { Terhadap } \\
\text { Y } \\
\end{array}$} & \multicolumn{7}{|c|}{ Pengaruh Tidak Langsung } & \multirow{2}{*}{$\begin{array}{c}\text { Total } \\
\text { Pengaruh }\end{array}$} & \multirow{2}{*}{$\begin{array}{c}t \text { tabel } \\
1,988 \\
t \text { hitung }\end{array}$} & \multirow{2}{*}{$\begin{array}{c}\text { Sign } \\
\text { Alpha } \\
0,05\end{array}$} & \multirow{2}{*}{$\begin{array}{l}\text { Kepu- } \\
\text { tusan }\end{array}$} \\
\hline & & $\mathbf{X}_{1}$ & $X_{2}$ & $\mathbf{X}_{3}$ & $\mathbf{X}_{4}$ & $X_{5}$ & $X_{6}$ & $\mathbf{X}_{7}$ & & & & \\
\hline $\mathrm{X} 1$ & 0,048 & - & 0,026 & 0,013 & 0,016 & 0,007 & 0,036 & 0,024 & 0,122 & 2,746 & 0,007 & Ho Ditolak \\
\hline $\mathrm{X} 2$ & 0,130 & 0,026 & & 0,018 & 0,113 & 0,038 & 0,007 & 0,017 & 0,219 & 4,377 & 0,000 & Ho Ditolak \\
\hline $\mathrm{X} 3$ & 0,033 & 0,013 & 0,018 & & 0,005 & 0,004 & 0,002 & 0,005 & 0,047 & 2,357 & 0,021 & Ho Ditolak \\
\hline $\mathrm{X} 4$ & 0,065 & 0,016 & 0,113 & 0,005 & & 0,035 & 0,005 & 0,015 & 0,189 & 3,017 & 0,003 & Ho Ditolak \\
\hline $\mathrm{X} 5$ & 0,083 & 0,006 & 0,038 & 0,004 & 0,035 & & 0,004 & 0,006 & 0,093 & 3,487 & 0,001 & Ho Ditolak \\
\hline $\mathrm{X} 6$ & 0,024 & 0,036 & 0,004 & 0,007 & 0,005 & 0,004 & & 0,005 & 0,061 & 2,174 & 0,032 & Ho Ditolak \\
\hline $\mathrm{X} 7$ & 0,033 & 0,024 & 0,017 & 0,005 & 0,015 & 0,006 & 0,005 & & 0,072 & 2,500 & 0,014 & Ho Ditolak \\
\hline & & & & & & & & & $R^{2}=0,793$ & & & \\
\hline
\end{tabular}

Sumber: Hasil Pengolahan Data 2008

\section{IMPLIKASI HASIL PENELITIAN}

Dilihat dari dimensinya maka yang menjadi faktor pembentuk brand personality sampo Sunsilk secara berurutan adalah sincerity (ketulusan hati), excitement (kegembiraan), competence (kemampuan), sophistication (keduniawian), ruggedness (ketangguhan). Dari faktor pembentuk tersebut bahwa faktor yang paling tinggi dalam mempengaruhi pembentukan loyalitas pelanggan sampo Sunsilk adalah dimensi competence yaitu sebesar nilai $16,79 \%$ dengan pengaruh langsung competence terhadap loyalitas pelanggan sebesar $9,73 \%$.

Faktor pembentuk loyalitas pelanggan adalah frekuensi pembelian berulang dalam bentuk pembelian produk secara berulang dan teratur. Pembelian antar lini produk dan jasa dalam membeli produk selain produk sampo yang ditawarkan oleh perusahaan seperti produk untuk perawatan rambut lainnya. Rekomendasi terhadap orang lain yaitu merekomendasikan produk kepada orang lain dengan memberitahukan bahwa produk yang digunakan itu baik. Kekebalan terhadap penawaran produk lain yaitu dalam bentuk menolak menggunakan produk lain yang sejenis meskipun menawarkan kualitas yang lebih baik karena pelanggan tetap loyal terhadap produk yang digunakannya. Dilihat dari faktor-faktor pembentuk tersebut pengguna melihat dimensi frekuensi pembelian secara berulang ditinjau dari pembelian pengguna secara rutin dan terartur merupakan faktor pembentuk loayalitas pelanggan dan memiliki skor tertinggi dibandingkan dengan dimensi lainnya.

Brand personality memiliki pengaruh yang signifikan terhadap loyalitas pelanggan baik secara parsial maupun simultan, hal ini diperkuat dengan teori yang dinyatakan oleh Barnes (2003:317) mengenai pentingnya brand personality bahwa Brand personality merupakan langkah penting jika kita mengakui bahwa pelanggan mengembangkan hubungan dengan merek. Pada kenyataannya, kita cenderung mengembangkan hubungan sejati dengan merek yang memiliki karakteristik sama dengan seseorang. Kita semua memiliki merek yang selalu kita pakai dan pakai lagi, yang telah kita pakai selama bertahun-tahun dan mendefinisikan siapa kita ini.

Berdasarkan temuan-temuan tersebut, maka diyakini hasil penelitian penulis mampu memberikan sumbangan ilmiah bagi pengembangan ilmu manajemen pemasaran, khususnya pemasaran produk dan pengembangan merek dan juga sebagai masukan yang konstruktif dan inspiratif bagi para manajer merek (brand manager) dalam mempertahankan dan meningkatkan kualitas dari produk dan mereknya untuk tetap bertahan.

\section{SIMPULAN DAN SARAN}

Berdasarkan hasil penelitian dengan metode analisis deskriptif dan verifikatif dapat disimpulkan:

1. Brand personality sampo sunsilk secara umum sudah berkategori cukup baik. Dimensi brand personality yang paling tinggi skornya ialah competence (kemampuan) dibandingkan dengan sincerity, excitement, sophistication dan ruggedness. competence (kemampuan) dalam hal ini adalah kualitas dan pengalaman sampo sunsilk yang telah diproduksi bertahuntahun dipercaya oleh pelanggan atau pengguna sampo Sunsilk

2. Loyalitas pelanggan sampo sunsilk secara umum sudah berkategori cukup baik. Dimensi 
loyalitas pelanggan yang memiliki skor paling tinggi adalah frekuensi pembelian (pembelian berulang) dibandingkan dengan pembelian diluar lini produk, rekomendasi terhadap orang lain, atau keyakinan untuk tetap menggunakan sampo sunsilk dalam hal ini yaitu pembelian secara teratur. Hal ini akan berpengaruh terhadap loyalitas pelanggan jika konsumen terus melakukan pembelian secara teratur maka kesetiaan terhadap Sunsilk akan tetap terjaga dan semakin tinggi tingkat kesetiaannya.

3. Hasil pengujian secara keseluruhan menunjukkan bahwa brand personality memiliki pengaruh yang positif terhadap loyalitas pelanggan. Berdasarkan hasil perhitungan bahwa brand personality memiliki pengaruh paling besar terhadap loyalitas pelanggan adalah dimensi competence. Pengguna menganggap jika kemampuan Sunsilk dalam menjaga dan terus meningkatkan rasa percaya konsumen terhadap sampo Sunsilk yang telah berpengalaman dalam memproduksi sampo secara bertahun-tahun maka tingkat loyalitas dari pengguna akan semakin tinggi.

\section{Saran}

Saran penulis untuk meningkatkan loyalitas yang tinggi pada pengguna shampo Sunsilk maka Unilever dalam hal ini perusahaan yang memproduksi shampo Sunsilk harus mempertahankan kepercayaan pelanggan terhadap shampo Sunsilk dengan menjaga dan meningkatkan kualitas dari produk. Berdasarkan hasil penelitian, maka penulis merekomendasikan beberapa hal sebagai berikut:

1. Pelaksanaan brand personality merupakan salah satu cara yang tepat untuk menumbuhkan loyalitas yang tinggi di benak pelanggan, namun hal terpenting yang harus diperhatikan oleh perusahaan (Unilever) adalah menjaga brand pesonality yang telah ada bahkan meningkatkan kualitas produk yang lebih optimal dibandingkan dengan produk shampo pesaing. Berdasarkan hasil penelitian bahwa ruggedness merupakan dimensi yang memiliki skor tanggapan pengguna paling rendah. Pada dimensi ruggedness item pertanyaan yang mendapatkan skor paling rendah yaitu pada daya tahan produk. Untuk itu, penulis menyarankan kepada pihak Unilever untuk melakukan inovasi yaitu dengan cara meningkatkan daya tahan produk dan manfaat yang diberikan produk kepada konsumennya, agar konsumen lebih setia terhadap produk perusahaan.

2. Tanggapan pengguna terhadap loyalitas pelanggan secara umum sudah cukup baik, namun untuk mempertahankan loyalitas pelanggan agar selalu tinggi dapat dilakukan melalui strategi yaitu, Perusahaan hendaknya lebih meningkatkan nilai tambah untuk meyakinkan konsumen bahwa shampo Sunsilk memiliki manfaat bagi mereka yang membutuhkannya, misalnya lebih mendekatkan diri dengan para pelanggannya dengan menambah varian dan jenis produk di luar lini produk shampo seperti: conditioner, cream bath dan sebagainya agar konsumen lebih tahu produk Sunsilk selain shampo yang dapat menunjang untuk perawatan rambut.

3. Secara keseluruhan brand personality mempunyai pengaruh yang positif terhadap loyalitas pelanggan. Berdasarkan hasil penelitian diketahui bahwa dimensi ruggedness memiliki pengaruh yang paling rendah terhadap loyalitas. Untuk itu, penulis menyarankan agar Unilever yaitu perusahaan yang memproduksi Sunsilk hendaknya lebih menonjolkan kepribadian mereknya (brand personality) sebagai shampo yang lebih memahami perempuan, hal ini dapat dilakukan dengan cara lebih banyak melakukan promosi melalui periklanan dengan tepat sebagai contoh pemilihan endoser yang sesuai dengan citra Sunsilk agar masyarakat luas lebih loyal lagi terhadap shampo Sunsilk.

\section{DAFTAR PUSTAKA}

Aaker, A. David. 1996. Building Strong Brands. New York: The Free Press.

Aaker, A. David. 1997. Managing Brand Equity. New York: The Free Press.

Aaker, A. David. 2002. Brand Leadership. New York, The Free Press.

AB. Susanto dkk.. 2004. Value Marketing Paradigma Baru Pemasaran. Jakarta Selatan: PT. Mizan Publika.

Barnes, G. James. 2003. Secret of Customer Relationship Management. Yogyakarta: ANDI. 
Bilson Simamora. 2001. Panduan Riset Perilaku Konsumen. Jakarta: Gramedia.

Bowen John dan Shoemaker Stone. 1998. Loyalty: A Strategy Commitment. Cornell HRA Quartertly.

Buchari Alma. 2005. Manajemen Pemasaran dan Pemasaran Jasa. Bandung: Alfabeta.

Cravens, David W. 2003. Pemasaran Strategis. Jakarta: Erlangga.

Darmadi Durianto. 2004. Strategi Menaklukan Pasar Melalui Riset Ekuitas dan Perilaku Merek. Jakarta: Prenhallindo

Djaslim Saladin. 2003. Intisari Pemasaran dan Unsur-Unsur Pemasaran. Bandung: Linda Karya.

Erna Ferrinadewi. 2008. Merek dan Psikologi Konsumen. Yogyakarta: Graha llmu.

Fandy Tjiptono. 1998. Strategi Pemasaran. Yogyakarta: ANDI.

Fandy Tjiptono. 2002. Strategi Pemasaran. Edisi II. Yogyakarta: Andi Offset.

Fandy Tjiptono. 2007. Pemasaran Strategis. Yogyakarta: ANDI.

Frans M. Royan. 2004. Cluster Strategy. Jakarta: Gramedia Pustaka Utama.

Fredy Rangkuti. 2002. The Power of Brand. Jakarta: PT. Gramedia Pustaka Utama.

Gobe, Marc. 2005. Emotional Branding. Jakarta: Erlangga.

Griffin, Jill. 2005. Customer Loyalty. Jakarta: Erlangga.

Harun Al-Rasyid. 1994. Teknik Penarikan Sampel dan Penyusunan Skala. Bandung: UNPAD

Hermawan Kertajaya. 2000. Marketing Plus 2000 Siasat Memenangkan Persaingan Global. Jakarta: Gramedia Pustaka Utama

Hermawan Kertajaya. 2004. On Brand. Bandung: PT Mizan Pustaka

Husein Umar. 2001. Metode Penelitian dan Aplikasi dalam Pemasaran. Jakarta: PT Gramedia Pustaka Umum.

Husein Umar. 2002. Metode Riset Bisnis. Jakarta: PT Gramedia.

Knapp, Duane E. 2001. The Brand Mindset. Mc Graw Hill Companies Inc

Kotler, Philip. 2005. Marketing Management, Prentice Hall New Jersey.

Kotler, Philip, Keller dan Kevin Lane. 2006. Marketing Management. Pearson International Edition. New Jersey: Pearson Prentice Hall.

Ratih Hurriyati. 2005. Bauran Pemasaran dan Loyalitas Pelanggan. Bandung: CV. Alfabeta
Schiffman, Leon.G dan Kanuk, Leslie. 2004. Consumer Behaviour. Jakarta: Prentice hal Internasional

Sudjana. 2001. Metoda Statistika, Bandung: Tarsito.

Sugiyono. 2006. Metode Penelitian Bisnis. Bandung: Alfabeta.

Suharsimi Arikunto. 2002. Prosedur Penelitian Suatu Pendekatan Praktis. Jakarta: Rineka Cipta

Teguh Budiarto. 2006. Pemasaran Internasional. Yogya: BPFE.

Zeithaml, Valarie A. and Mary Jo Bitner. 2000. Services Marketing. Irwin Mc Graw-Hill Boston.

Jurnal

Moqvist, Louise. 2003. Kompetensi Guru Dalam Implementasi KBK. 6 Nopember 2003

Ouwersloot, Hans dan Tudorica, Anamaria. 2001. Brand Personality Creation Through Advertising. Maastrich academic Center for Research in Services Journal.

Majalah

SWA 16/XXII/23 Juli - 5 Agustus 2008; 17/XXIII/6Agustus-20 Agustus 2008; 20/XXII/21 September-4 Oktober 2006; SWA 19/XXIII/3-12 September 2007; 20/XXIV/18 September-8 Oktober 2008; SWA 16/XXII/23 Juli-5 Agustus 2008; SWA 17/XXIII/6Agustus-20 Agustus 2008; SWA 20/XXII/21 September-4 Oktober 2006; SWA 19/XXIII/3-12 September 2007; dan SWA 20/XXIV/18 September-8 Oktober 2008 